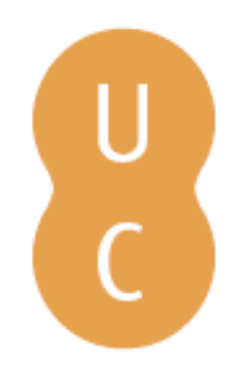

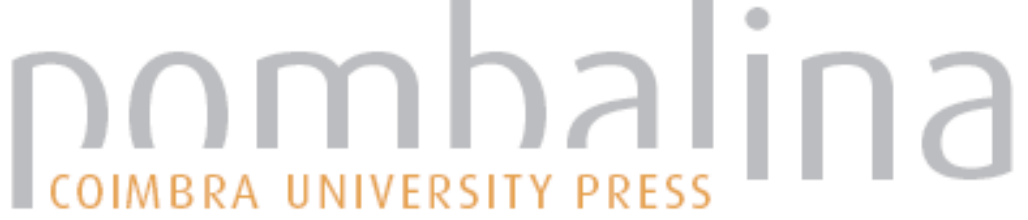

\section{Arquitetura da informação digital em ambientes científicos e acadêmicos}

Autor(es): $\quad \begin{array}{ll}\text { Camargo, Liriane Soares de Araújo de; Vidotti, Silvana Aparecida } \\ \text { Borsetti Gregorio }\end{array}$

Publicado por: Imprensa da Universidade de Coimbra

URL

persistente: URI:http://hdl.handle.net/10316.2/31931

DOI: $\quad$ DOI:http://dx.doi.org/10.14195/978-989-26-0869-3_23

Accessed : $\quad$ 26-Apr-2023 16:07:00

A navegação consulta e descarregamento dos títulos inseridos nas Bibliotecas Digitais UC Digitalis, UC Pombalina e UC Impactum, pressupõem a aceitação plena e sem reservas dos Termos e Condições de Uso destas Bibliotecas Digitais, disponíveis em https://digitalis.uc.pt/pt-pt/termos.

Conforme exposto nos referidos Termos e Condições de Uso, o descarregamento de títulos de acesso restrito requer uma licença válida de autorização devendo o utilizador aceder ao(s) documento(s) a partir de um endereço de IP da instituição detentora da supramencionada licença.

Ao utilizador é apenas permitido o descarregamento para uso pessoal, pelo que o emprego do(s) título(s) descarregado(s) para outro fim, designadamente comercial, carece de autorização do respetivo autor ou editor da obra.

Na medida em que todas as obras da UC Digitalis se encontram protegidas pelo Código do Direito de Autor e Direitos Conexos e demais legislação aplicável, toda a cópia, parcial ou total, deste documento, nos casos em que é legalmente admitida, deverá conter ou fazer-se acompanhar por este aviso.

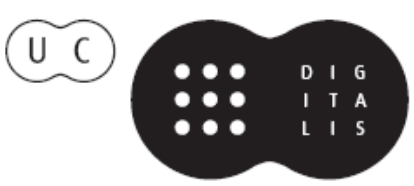


Maria Manuel Borges

Elias Sanz Casado

Coordenação

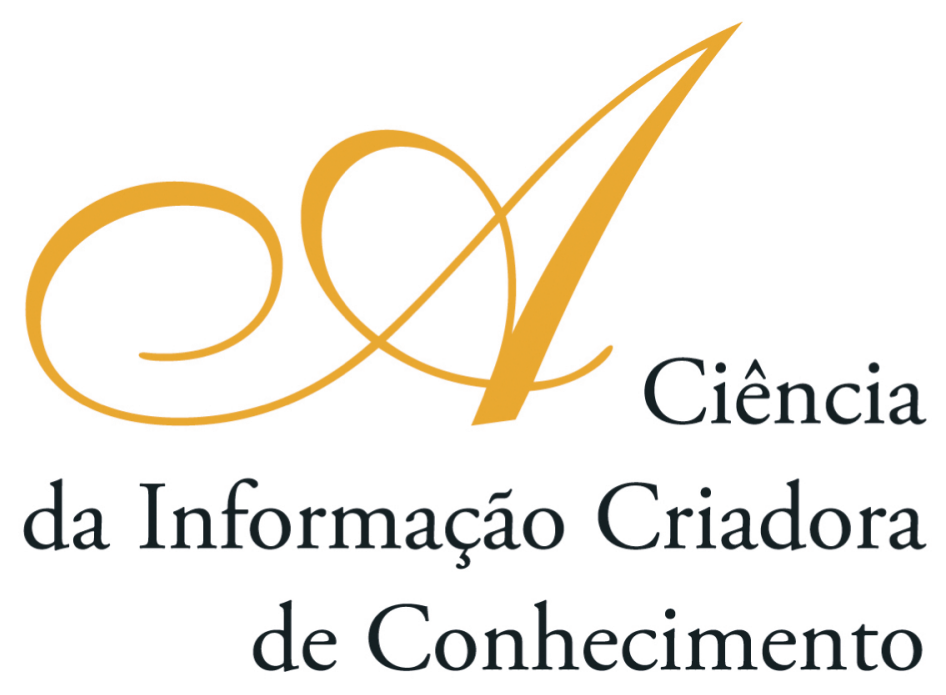

Vol. I I

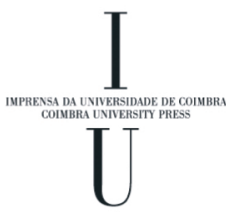

- COImbra 2009 


\title{
Arquitetura da Informaçáo Digital em Ambientes \\ Científicos e Acadêmicos
}

\author{
Liriane Soares de Araújo de Camargo \\ Universidade Estadual Paulista (Brasil)
}

Silvana Aparecida Borsetti Gregorio Vidotti

Universidade Estadual Paulista (Brasil)

\section{Resumo}

A Arquitetura da Informação (AI) visa auxiliar o desenvolvimento de ambientes digitais por meio do oferecimento de um conjunto de princípios, processos e métodos que regem sua conceituação. Contudo, tal conjunto ainda está sendo consolidado na área da Ciência da Informação, abrangendo várias áreas de conhecimento. Baseado nesse contexto, este artigo apresenta algumas práticas e diretrizes para o desenvolvimento de AI para ambientes de ensino e pesquisa. Tais ambientes foram selecionados para direcionar uma AI mais específica, que deve abordar o tratamento e a disseminação da informação como atividades essenciais. A apresentação das diretrizes e práticas consiste em uma análise literária e exploratória de processos e métodos de diversas áreas do conhecimento, os quais apóiam as etapas de análise e projeto de informaçóes acadêmicas e científicas. Uma arquitetura da informaçáo específica pode prover serviços direcionados como atendimento de alunos com necessidades especiais baseado em princípios de acessibilidade, ambiente colaborativo baseado em princípios da web 2.0, customização de interface baseada em estudos de usabilidade, recomendação de informaçóes baseada em recursos de personalização e auto-arquivamento de documentos baseado em princípios de repositórios digitais. Espera-se que as informaçóes apresentadas auxiliem na elaboração de ambientes informacionais digitais, facilitando e aumentando a interação usuário-sistema, a comunicação científica e a construção de conhecimentos.

\section{Abstract}

Information Architecture (IA) aims to support the development of digital environments by offering of a set of principles, processes and procedures governing its conceptualization. However, this set is still being consolidated in the area of Information Science, covering various fields of knowledge. Based on that context, this paper presents some practices and guidelines for development of AI for environments for education and research. These environments were selected to target a more specific IA, which should address the treatment and dissemination of information as essential activities. The presentation of guidelines and practices involves literary and exploratory analysis of processes and methods in various areas of knowledge, which support the steps of 
analysis and design of academic and scientific information. A specific information architecture can provide services targeted to students with special needs based on principles of accessibility, collaborative environment based on Web 2.0, customization of interfaces based on usability studies, recommendation of information based on personalization resources and self-archiving of documents based on principles of digital repositories. It is hoped that the information presented assist in developing of digital informational environment, facilitating and enhancing the user-system interaction, communication and construction of scientific knowledge.

\section{Introdução}

De acordo com Tosete Herranz e Rodríguez Mateos (2004, p.207) “a Arquitetura da Informação (AI) é uma disciplina que trata de projetos de espaços de informação em ambiente digital". A AI deve abordar o tratamento de conteúdo e de interface no desenvolvimento e avaliação de ambientes informacionais digitais, a fim de facilitar o desenvolvimento e aumentar a usabilidade dos mesmos.

Muitos arquitetos da informação utilizam práticas e diretrizes advindas de outras áreas do conhecimento como Administração, Design Gráfico, Computação e Biblioteconomia para auxiliar no desenvolvimento de ambientes informacionais digitais. Por exemplo, pode-se utilizar os métodos de análise de requisitos e cenários de usuários advindos da Computação, bem como taxonomias e vocabulários controlados advindo da Biblioteconomia para o tratamento de conteúdo, considerando o usuário final.

Baseado nesse contexto, este artigo possui como objetivo apresentar práticas e diretrizes de AI para auxiliar no desenvolvimento e na usabilidade de ambientes científicos e acadêmicos como sites de instituição de ensino superior, bem como periódicos, bibliotecas e repositórios digitais abordados por esses tipos de instituiçôes.

A metodologia utilizada consiste na análise literária de algumas práticas e diretrizes de AI utilizadas no desenvolvimento de ambientes científicos e acadêmicos, bem como na análise desses tipos de ambientes, identificando objetivos e características específicas.

Espera-se auxiliar no estabelecimento de um conjunto de práticas e diretrizes para o campo de Arquitetura da Informação, bem como auxiliar arquitetos da informação no tratamento de conteúdo e de serviços de ambientes digitais, a fim de melhorar a qualidade do mesmo e consequentemente melhorar a comunicação e produção científica e acadêmica.

\section{Arquitetura da Informação}

Para compreender o conceito 'Arquitetura da Informação' é necessário entender sua origem. A AI começou a ganhar força entre a década de 60 e 70, quando os sistemas de informação começaram a determinar vantagem competitiva nas organizaçôes que os utilizavam, desde que seu design gráfico e de informação fossem elaborados de acordo com as necessidades dos usuários. Nessa época, começou a se perceber que, para 
garantir a qualidade dos sistemas de informação, era necessário tratar as informações que entravam e saíam da aplicação por meio de uma interface interativa e de boa qualidade. Baseado nesse contexto o primeiro conceito a ser popularizado do termo foi dado por Wurman em 1976 como sendo uma 'estrutura' ou 'mapa de informação', permitindo as pessoas/usuários encontrar seus caminhos para a construção de conhecimentos em ambientes informacionais (WURMAN, 1996).

Essa estrutura ou mapa de informação visa a organizar as informaçóes para que os usuários possam acessá-las mais facilmente. Essa organização por meio de mapas ou estruturas foi considerada por Wurman como uma forma análoga de projetar espaços organizados e estruturados semelhante a prática do profissional arquiteto. A partir disso, ele cunhou o termo 'Arquitetura' e 'Informação', popularizando assim o termo 'Arquitetura da Informação'.

Wurman (1996) entende os problemas de reunião, organização e apresentação da informação como análogos aos de um arquiteto ao projetar um edifício que serve às necessidades de seus ocupantes. De forma complementar a essa afirmação, Siqueira (2008, p.30) relata que "a visão de Wurman é derivada de sua formação como arquiteto e seu principal propósito é estender os conceitos chaves de organização de espaços, desenvolvidos na arquitetura, para os espaços informacionais".

Alguns autores conceituam AI de forma semelhante aos conceitos e práticas utilizados na área de Arquitetura como planta, espaço, desenho estrutural e construção. Por exemplo, Toms e Blades (1999 p.247, tradução nossa) definem AI como "a planta, o mapa para a organização digital da informação, incluindo as formas como o usuário navegará e acessará a informação”.

McGee e Prusak (1994, p.129) relatam que o termo 'Arquitetura da Informação' "é um termo complexo, pois combina duas palavras que possuem uma vasta gama de conotaçôes”. Assim, se for considerada a palavra 'arquitetura' como a arte e a ciência de desenhar e projetar espaços/ambientes, como seria desenhar e projetar informaçáo? A palavra 'informação' é conceituada de forma distinta de acordo com diversos autores da área, sendo o primeiro problema encontrado para a definiçáo de AI.

A AI se refere ao tratamento de objetos de conteúdo em ambientes informacionais digitais, e entre as definiçóes encontradas na literatura podem-se destacar alguns termos como 'ambientes informacionais compartilhados', 'websites', 'intranets', 'experiências de produtos de informação' e 'ambiente digital'. Nesse sentido, Brancheau e Wetherbe (1986 apud Lima-Marques e Macedo, 2006, p.248) adotam o conceito de AI como "uma metodologia para estruturação de sistemas de informação aplicada a qualquer ambiente informacional, sendo este compreendido como o espaço que integra contexto, conteúdos e usuários".

Complementar a isso, Siqueira (2008, p.33) afirma que "não é possível delimitar a Arquitetura da Informação ao uso pragmático de tratamento de documentos, muito menos, restringí-la ao contexto da criação de sítios na Internet". "A aplicação da Arquitetura da Informação viabiliza a redução do custo de acesso à informação, potencializando o seu valor para o usuário". Assim, a AI não se restringe apenas ao desenvolvimento de ambientes informacionais (beneficiando apenas o desenvolvedor), ela também aborda o usuário, facilitando a utilização e aumentando a usabilidade do ambiente informacional, incentivando a utilização de recursos interativos para melhorar a comunicação e produção de informaçôes. 


\section{Ambientes Informacionais Digitais}

Neste artigo são enfocados os ambientes informacionais inseridos na plataforma web, em que o objetivo principal consiste em atender as necessidades informacionais dos usuários, aumentando a fidelidade do mesmo em relação ao sistema. Vale ressaltar que a Internet suporta ambientes informacionais de grande escopo, e complementar a isso, Oliveira (2005, p.15) afirma que "a Internet abriu a seus usuários a possibilidade de produzir, digitalizar e veicular informação, da maneira que melhor lhes conviesse. $\mathrm{O}$ usuário passa então a desempenhar tanto o papel de produtor quanto o de distribuidor da informação". Ainda nesse contexto, D’Andréa (2006, p.43) relata que

A facilidade de produção, publicação e difusão de informações, que resultou também na proliferação de unidades "informais" de informação, assim como a possibilidade de acesso remoto a bases de dados e acervos, alterou significativamente as características das unidades tradicionais, os processos por elas executados e o perfil dos profissionais envolvidos.

As condiçôes e objetivos de uma unidade de informação são variáveis fundamentais no funcionamento final da mesma, uma vez que seus "filtros" institucionais, políticos, econômicos etc. influenciam em toda a cadeia documental.

Apesar da existência da grande quantidade de ambientes informacionais que enfocam o gerenciamento de informaçóes empresarias, pode-se perceber o aumento de ambientes situados fora do contexto empresarial, os quais não visam o lucro em si, mas a disseminação de informaçóes para sociedade em geral como os ambientes científicos e acadêmicos (por exemplo, fóruns de pesquisas, wikis, bibliotecas e repositórios digitais).

Assim, espera-se que uma AI específica para ambientes científicos e acadêmicos, que considere princípios de colaboração, personalização, tratamento semântico, estudo de usuários, acessibilidade, usabilidade, entre outros princípios, possa auxiliar de forma significativa na comunicação e produção informacional por meio formas de recuperação e acesso eficientes e eficazes.

Assim, considerando os ambientes digitais voltados para o oferecimento do produto 'informação', pode-se afirmar que seus objetivos estão relacionados com a melhoria dos processos de tratamento informacional e de interfaces, com o oferecimento e disponibilização de informaçôes atualizadas e confiáveis, no oferecimento e elaboração de novos serviços e funçôes, na melhoria na interação usuário-sistema, aumentado assim a usabilidade do ambiente, bem como na tomada de decisóes pautadas em informaçóes seguras, na garantia da vantagem competitiva, fidelidade do usuário e sobrevivência.

A comunicação entre pesquisadores, usuários em geral e/ou comunidades específicas é essencial para a geração de conhecimentos. Alguns fatores que influi na comunicação são: informaçóes relevantes dos usuários, como perfil, comportamento, experiências, preferências, modo de interação, interpretação e combinaçôes de informaçóes; oferecimento de feedback; utilidade, usabilidade, acessibilidade, confiabilidade, atualização e coerências das informaçôes; facilidade de entendimento; interfaces agradáveis, entre outros. 


\section{Arquitetura da Informação para Ambientes Científicos e Acadêmicos}

Existem vários tipos de ambientes científicos e acadêmicos na web, possuindo características e objetivos específicos, entretanto pode-se considerar alguns objetivos em comum como: armazenar, facilitar o acesso e disseminar informaçóes. Cada tipo de ambiente possui um determinado enfoque. Por exemplo: a biblioteca digital visa à criação, seleção e tratamento das informaçôes para disponibilizá-las para o público em geral; o periódico científico visa o estabelecimento de critérios de qualidade para consolidação da ciência e áreas de pesquisa; os repositórios digitais possibilitam visibilidade da propriedade intelectual de instituiçóes e/ou comunidades; os websites de IES visam a divulgar informaçóes específicas e garantir a visibilidade da mesma.

Sendo assim, a primeira atividade a ser feita em uma AI é: 1 - coletar requisitos, identificando objetivos e metas do ambiente, informaçôes necessárias, serviços oferecidos e público-alvo atendido.

Os ambientes informacionais digitais devem ser desenvolvidos utilizando-se da abordagem centrada no usuário, pois segundo Loureiro e Albagli (2008, p.6) "a caracterização de um ambiente informacional envolve identificar os principais atores, suas atribuiçóes e relaçóes, bem como os demais elementos que definem as condiçôes de acesso, necessidades e usos da informação".

Além da coleta, deve-se fazer um planejamento inicial para viabilizar o desenvolvimento do ambiente, apresentando cronograma e custos.

Para auxiliar o arquiteto da informação nessas atividades, várias práticas podem ser utilizadas, como: entrevistas e questionários (consiste em formulação de perguntas), grupo focal (consiste em reunióes com representantes de usuários finais (ou interessados) para identificar informaçôes), cenários de usuários (consiste em descrever atividades ou interação de usuários), árvore de dados (consiste em organizar os requisitos coletados em forma de uma árvore) e benchmark (consiste em analisar outros ambientes concorrentes).

A próxima atividade a ser feita é analisar os requisitos coletados. Para auxiliar nessa atividade pode-se utilizar uma listagem dos serviços, funçóes e conteúdos a serem disponibilizados.

Muitas das atividades de ambientes científicos são similares como: oferecer acesso remoto e simultâneo, gerenciar conteúdo, preservar as informações, recuperar as informaçōes, tratar o conteúdo considerando a segurança e confiabilidade das mesmas, oferecer coleçóes de documentos bibliográficos e completo, oferecer produtos e serviços, utilizar metadados e possuir diversas fontes e formatos. Baseado nisso, a Fig. 1 apresenta de forma visual alguns recursos e princípios específicos e comuns. 


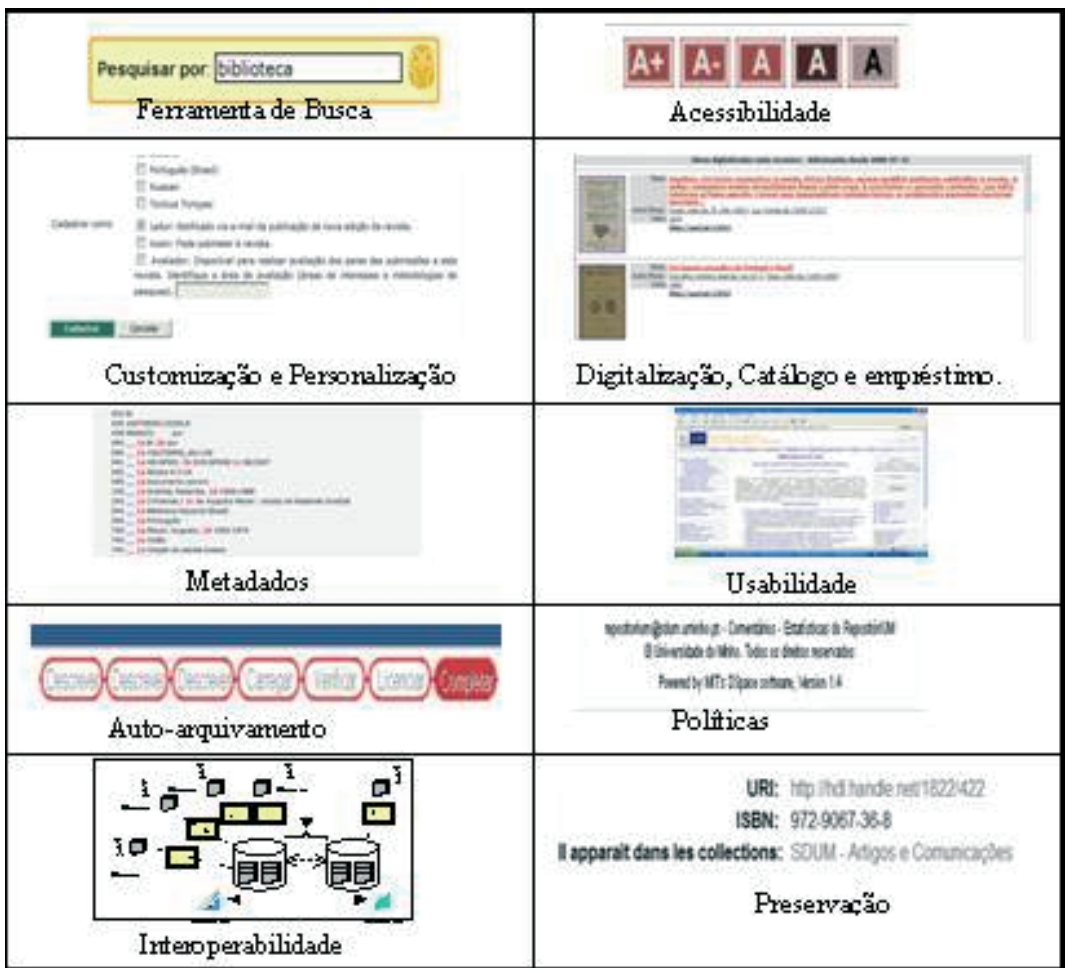

Fig. 1 - Recursos característicos de ambientes científicos digitais

É importante comentar que um ambiente de ensino e pesquisa pode abranger outros tipos de ambientes. Por exemplo: um website de uma IES pode abranger uma biblioteca digital, um periódico científico, um repositório digital, bem como outros tipos de ambientes como fórum, blog e wiki.

Assim, o arquiteto da informaçáo pode utilizar um modelo de arquitetura para representar os sub-sistemas do ambiente, definindo o domínio do mesmo. Um exemplo desse modelo é apresentado na Fig. 2.

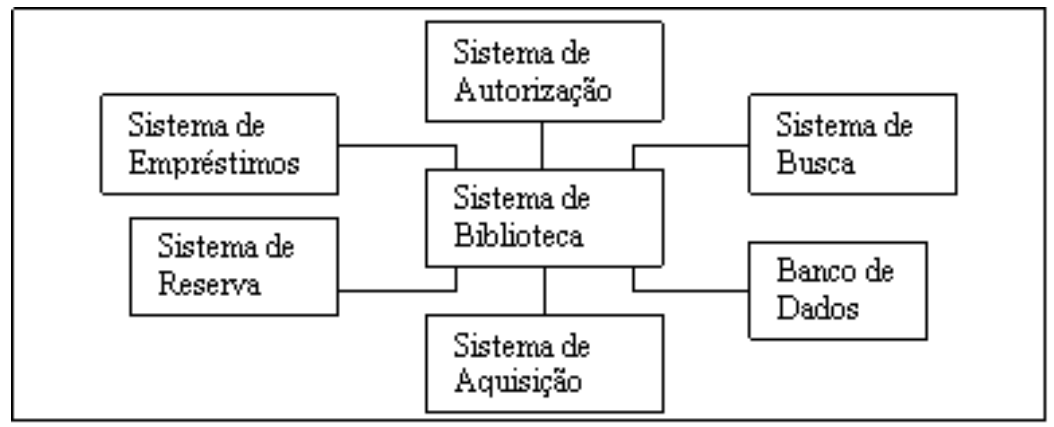

Fig. 2 - Exemplo de Modelo de Arquitetura 
É importante comentar que outras práticas também podem ser utilizadas para modelar o contexto e os fluxos informacionais do ambiente como o Diagrama de contexto, de fluxos de dados, de Seqüência, entre outros diagramas advindos da Ciência da Computação. Baseado na Fig. 2, apresentam-se a seguir alguns recursos essenciais para ambientes científicos digitais:

- Ferramenta de Busca: são programas computacionais que visam possibilitar a recuperação de documentos solicitados segundo as estratégicas de busca adotadas pelos usuários. A estratégia de busca depende do tipo de usuário e da própria ferramenta, podendo possibilitar uma estratégia simples e/ou avançada. Rosenfeld e Morville (1998) comentam sobre o sistema de busca, que demonstra a variedade de expectativas dos usuários, que podem: buscar por itens conhecidos, em que as necessidades são claramente definidas; buscar por idéias abstratas, em que o usuário sabe o que quer, mas tem dificuldade em descrever; buscar de forma exploratória, em que o usuário sabe como expressar, mas náo sabe exatamente o que espera encontrar; e buscar de forma compreensiva, em que os usuários querem todas as informaçóes disponíveis sobre um determinado assunto.

- Acessibilidade: Iniciativas governamentais surgem para minimizar problemas de acesso e inclusáo digital, visando auxiliar usuários portadores de necessidades especiais por meio de recomendaçóes de princípios específicos de acessibilidade. Torres et al. (2002) relatam que a acessibilidade consiste em tornar disponível ao usuário, de forma autônoma, toda a informação que lhe for franqueável, independentemente de suas características corporais (individuais/orgânicas), sem prejuízos quanto ao conteúdo da informação. $\mathrm{O}$ autor relata ainda que devem ser feitas adequaçóes de requisitos para usuários com limitaçóes associadas à motricidade, audição e visão. Winckler e Pimenta (2002, p.2) relatam que "a maioria das recomendaçóes ergonômicas e recomendação para acessibilidade não limita a utilização da interface apenas a pessoas com necessidades especiais". Na verdade, algumas das recomendaçóes podem ser mesmo úteis por qualquer usuário, como os exemplos a seguir: descrever imagens e animaçóes (atributo 'alt'), incluir transcrição de áudio e descrição de vídeos; usar cabeçalho, listas e estruturas consistentes etc. Outras recomendaçóes de acessibilidade podem ser encontradas nos guias de acessibilidade web, os quais consistem em: Web Content Accessibility Guidelines - WCAG, Authoring Tool Accessibility Guidelines - ATAG) e User Agent Accessibility Guidelines - UAAG.

- Usabilidade: Esse termo começou a ser utilizado no início da década de 80, principalmente nas áreas de Psicologia Cognitiva e Ergonomia como um substituto da expressão "userfriendly», considerando facilidade de aprendizagem; rapidez no desempenho da tarefa; baixa taxa de erro; interface adequada ao sistema; e satisfação subjetiva do usuário. Para Silvino e Abrahão (2003, p.13) "a usabilidade, aferida pelos critérios ergonômicos e de funcionalidade, indica o grau de facilidade que a página oferece ao ser acessada”. Os problemas de usabilidade mais recorrentes correspondem a: falta de atualização, interação usuário-sistema ineficiente, falha na navegabilidade e nas funcionalidades, ausência de suporte e feedback, dificuldade em acessar a informação desejada, interfaces complicadas e difíceis de utilizá-las e ocorrência constante de erros

- Customizaçáo e Personalizaçáo: Schilk et al. (2004, p.381, tradução nossa) enfatizam que "personalização não deve ser confundida com customização". 
Customização geralmente lida com a aparência do site (por exemplo, cores e fontes). «Na customizaçáo, o usuário controla e personaliza o site ou o produto baseado em suas preferências» (Mobasher et al. 2001). Assim, considerado-se que a personalização envolve atividades de filtragem, processamento e direcionamento de informaçóes específicas e que a customização envolve atividades de modificação aos componentes visuais e informacionais da interface para e pelos usuários.

- Metadados: Rosetto (2003, p. 59) define metadados como "um conjunto de dados - atributos - referenciais, metodologicamente estruturados e codificados, conforme padróes internacionais, para localizar, identificar e recuperar pontos informacionais de textos, documentos e imagens disponíveis em meios digitais ou em outros meios convencionais". Com a necessidade de denominar o tratamento da informação em meio digital, o termo metadados é utilizado com intensidade como um termo que permite a comunicação entre diferentes áreas que possuem o mesmo objetivo: dar tratamento às informaçôes tendo em vista o gerenciamento informacional (ALVES, 2005). Para os profissionais da Ciência da Informação, o termo metadados está relacionado com o tratamento da informação, mais especificamente às formas de representação de um recurso informacional para fins de identificação, localização e recuperação, ou seja, dados sobre catalogação e indexação que servem para organizar e tornar a informação mais acessível (GILLILAND-SWETLAND, 1999 apud CASTRO, 2008).

- Política: A maioria dos ambientes científicos digitais é desenvolvida por iniciativas de instituiçóes responsáveis e confiáveis, as quais definem políticas para o ambiente, abrangendo formas de uso e gerenciamento informacional, bem como questóes sobre direitos autorais. As políticas orientam as coleçôes e garante a visibilidade do ambiente, prevendo: forma de acesso; tipo de documentos; restriçóes ao nível do conteúdo do documento; formas de depósito de documentos; tipologias de formatos; formato de documentos; digitalização de documentos; normalização de formatos; segurança e preservação da informação; normalização para documentos eletrônicos; e incentivo.

- Interoperabilidade - Normas, padróes e regras sempre foram desenvolvidos, principalmente pelas áreas da Biblioteconomia e Ciência da Informação, a fim de garantir a precisão dos recursos informacionais para um acesso e recuperação efetivos, sobretudo em ambientes informacionais específicos, tais como as bibliotecas digitais. A interoperabilidade é a capacidade de compartilhamento de informaçóes em diferentes sistemas e que, por meio de algumas ferramentas como linguagem de marcação adequada como XML (Extensible Markup Language), uso de metadados e arquiteturas de metadados. As informaçóes registradas e armazenadas em diferentes estruturas e em diferentes comunidades do conhecimento poderão ser intercambiadas, possibilitando um trabalho conjunto entre sistemas e usuários.

- Preservaçáo - Muitos ambientes digitais não possuem URL permanente e de acordo com Coelho (2006, p.9) algumas plataformas de desenvolvimento pode garantir "que a referência (URL) permaneça da mesma forma a longo prazo, pois os utilizadores necessitam de referências permanentes e estáveis para os seus trabalhos e estes tornam-se fundamentais para as suas citaçôes”. Assim, a permanência das URLs é uma forma de preservação da informação, que segundo Boeres e Márdero Arellano (2005, p.2) "é a parte mais longa e também a última do ciclo de gerenciamento de objetos digitais, com ela é garantido o emprego de mecanismos que permitem o 
armazenamento em repositórios de objetos digitais e que garantem a autenticidade e perenidade dos seus conteúdos".

Além desses recursos e princípios, os ambientes informacionais digitais podem utilizar os sistemas de organização, busca, navegação, rotulagem e representação apresentados na arquitetura da informação de Morville e Rosenfeld (2006). Assim, na atividade de análise devem ser consideradas também as formas de navegação do ambiente, que segundo Pressman (2006) podem ser linear, em malha, hierárquica e em rede como mostra a Fig. 3.

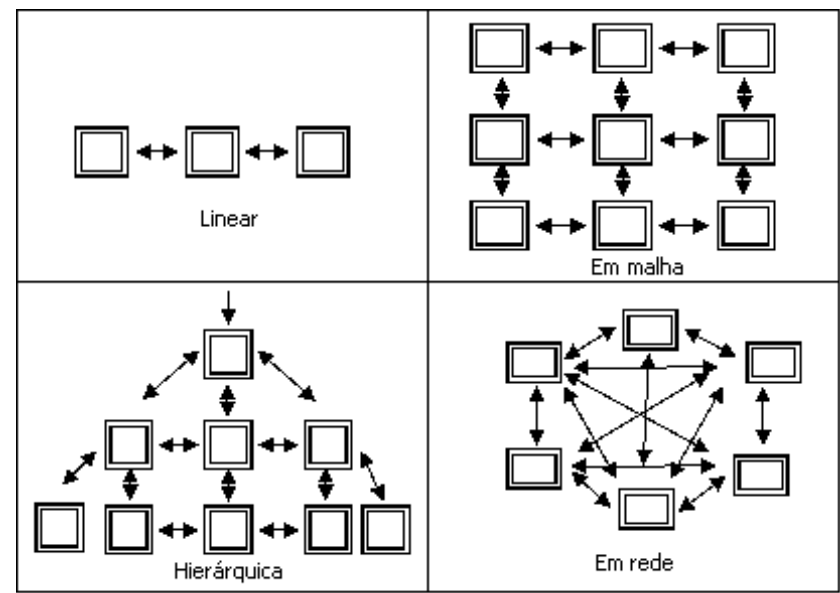

Fig. 3 - Formas de navegação

Pressman (2006) relata que a estrutura linear é utilizada quando há uma seqüência previsível de interaçôes. Um exemplo é a apresentação de um tutorial em várias partes. A estrutura em malha é utilizada quando o conteúdo pode ser organizado em categorias de duas ou mais dimensóes. Um exemplo seria um repositório digital em que os objetos digitais podem ser acessados por coleção, autor, título e/ou data de publicação, oferecendo ao usuário opçōes de navegação. A estrutura hierárquica permite que o usuário navegue de forma hierárquica, tanto vertical como horizontalmente. A estrutura em rede é utilizada quando cada componente (páginas) é projetado de modo que possa passar comandos (via links de hipertexto) para qualquer outro componente do sistema.

Vale ressaltar que Rosenfeld e Morville (1998) também abordam esses tipos de estruturas, porém atribuem outros nomes como estrutura base de dados relacional para organizar informaçóes em registros, estrutura hipertextual no contexto dos sistemas de organização e estrutura ad hoc no contexto dos sistemas de navegação para representar uma forma náo linear de estruturar conteúdo em rede, na qual itens ou partes de informação são interligados por meio de links.

Os arquitetos da informação podem utilizar-se de: mapa do site (que representa o caminho que o usuário realiza para chegar até a informação desejada), BluePrints (que mostra relacionamentos entre páginas e outros componentes de conteúdo), entre outras práticas. 
Ainda na fase de análise deve-se tratar o conteúdo. Batley (2007, p.95-96, tradução nossa) relata que o primeiro passo para isso é dividir espécie de documentos de acordo com: Formato (por exemplo: áudio, texto); Tipo documental (por exemplo: artigos, teses); Fonte (por exemplo: departamento de recursos humanos, marketing); Assunto (por exemplo: Ciência da Informação, Ciência da Computação), entre outros. O importante e dividir e separar os conteúdos para depois agrupá-los e os rotular em uma categoria.

Baseado nessa atividade, arquitetos da informação podem utilizar ferramentas de apoio como: inventário de conteúdo (consiste em um levantamento detalhado das informaçóes disponibilizadas no ambiente digital), mapa de conteúdo (consiste na representação visual do conteúdo do site), card sorting (consiste na organização e agrupamento de informaçóes por meio de cartóes para entender as percepçóes de usuários em relação aos itens de conteúdo), entre outros.

Além da divisão dos objetos de conteúdos, deve-se realizar os processos de classificação, catalogação e indexação. Para isso, Batley (2007, p.74) relata que o tipo de taxonomia mais familiar para recuperar informação é exemplificada no arranjo de árvores de assuntos nos diretórios web, como é mostrado na Fig. 4.

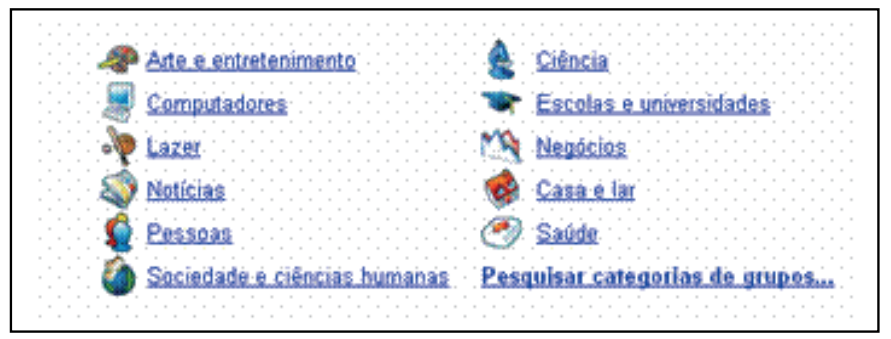

Fig. 4 - Exemplo de assuntos em diretório web

Fonte: http://groups.google.com.br/grphp?hl=pt-BR\&tab=wg

A taxonomia organiza informação e conhecimento de forma significativa, pois uma vez que ela é construída, os usuários têm acesso à informação estruturada e armazenada. Os arquitetos da informação também podem utilizar-se de: vocabulário controlado, ontologia e folksonomia. Segundo Batley (2007, p.107, tradução nossa) "há dois agentes de vocabulário controlado: lista de cabeçalho de assunto e tesauro", ambos possuem as mesmas funçóes, as quais consistem em: controlar a terminologia usada nos índices e controlar a exibição dos relacionamentos entre conceitos nos índices. A ontologia também define relacionamento entre termos e segundo Castro (2008, p.121) "o uso de ontologias permite o estabelecimento da semântica, ou o significado dos dados descritos e representados pelos metadados". "A ontologia pode ser considerada como um instrumento para a descrição bibliográfica dos recursos informacionais, pois se cria uma rede de conceitos com propriedades apropriadas e restritas" (Castro, 2008, p.125). E a folksonomia envolve a atribuição de etiquetas pelo próprio usuário, consistindo em um processo de indexação colaborativa.

Em relação ao processo de catalogação, deve-se dominar os princípios e critérios para a descrição dos dados bibliográficos associados a um documento com a finalidade de uma fácil identificação e recuperação. Segundo Castro (2008, p.79) o principal 
recurso utilizado é o catálogo que "é um dos instrumentos mais antigos na história da descrição e organização da informação registrada", definindo-o "como lista ordenada dos documentos existentes em um ou mais acervos".

Relacionado ao processo de indexação, segundo Pinto (2001), esse pode ser: Manual (é realizada pelos humanos e se baseia no julgamento, normalmente intuitivo, dos indexadores, em função do texto e do interesse para a sua comunidade de usuários), Automática (é uma indexação mecânica feita por meio de ferramentas de informática), e Semi-automática (que combina os dois tipos de indexação: humana e mecânica). Novellino (1996) comenta que o processo de indexação pode ser feito em três concepçóes: (1) Na concepção simplista pode-se extrair automaticamente palavras ou expressôes dos textos. (2) Na concepção votada ao conteúdo (indexação de assuntos) são identificados tópicos ou assuntos que não são explicitamente colocados na estrutura textual superficial de um documento, mas que são prontamente perceptíveis por um indexador. (3) Na concepção orientada à necessidade, os documentos são criados para a comunicação do conhecimento, e as entradas de assunto devem ser feitas para funcionar como instrumentos para mediar e traduzir este conhecimento visível para quaisquer pessoas interessadas.

A próxima atividade a ser feita no desenvolvimento de uma AI para ambientes científicos digitais consiste no projeto, em que são tratados os aspectos visuais, definindo assim o tipo de rotulagem que pode ser: Textual (envolve rótulos em forma de textos), Iconográfico (envolve rótulos em forma de ícones/imagens) e Misto (envolve a rotulagem textual e iconográfico). Nesta atividade, os arquitetos da informação podem utilizar várias práticas como: wireframes (que representa como uma página individual ou template que deve aparecer a partir de uma perspectiva arquitetural), macro arquitetura da informação (que apresenta uma estrutura base/ principal da interface) e a micro arquitetura da informação (envolve a apresentação das estruturas secundárias).

Nesta etapa, os princípios de acessibilidade e usabilidade devem ser considerados, bem como a interação do usuário com o ambiente. A AI ainda deve avaliar o ambiente depois de implementado e retroalimentá-lo constantemente.

\section{Considerações Finais}

Este artigo apresentou diretrizes e práticas de uma arquitetura da informação voltada para ambientes científicos e acadêmicos, a fim de auxiliar arquitetos da informação no desenvolvimento de tais ambientes, abordando inserção de serviços, tratamento informacional, navegacional e de interface.

A AI é considerada neste artigo como uma metodologia que oferece processos e práticas de desenvolvimento de ambientes informacionais digitais, em que os processos consistem em etapas e atividades a serem seguidas e as práticas consistem em métodos e ferramentas que podem ser utilizadas em cada atividade.

Os ambientes abordados foram os científicos, em consequência da sua significativa relevância para a Ciência da Informação, em que o processo de tratamento de conteúdo é fundamental. Esses ambientes devem ser expandidos para atender da melhor forma possível as necessidades dos usuários finais. 
As atividades apresentadas na $\mathrm{AI}$ proposta consistem em: coletar requisitos, elaborar planejamento, analisar requisitos, projetar o ambiente, avaliar e retroalimentar o ambiente. Em cada etapa foram apresentadas algumas práticas que podem ser utilizadas para auxilio da atividade como entrevistas, card sorting, tesauros, catálogo, mapa do site e wireframe, bem como foram apresentados alguns assuntos e serviços importantes como metadados, preservação, interoperabilidade, políticas, ferramenta de busca, acessibilidade, usabilidade, personalização e customização.

\section{Referências bibliográficas}

ALVES, R. C. V. Web semântica: uma análise focada no uso de metadados. 2005. 180 f. Dissertação (Mestrado em Ciência da Informação) - Faculdade de Filosofia e Ciências, Universidade Estadual Paulista, Marília.

BATLEY, Sue. Information Architecture for Information Professionals. Oxford/England: Chandos Publishing, 2007.

BOERES, S.A; MÁRDERO ARELLANO, M, A. Políticas e estratégias de preservação de documentos digitais. In: CINFORM - ENCONTRO DE CIÊNCIA DA INFORMAÇÃO, VI , 2005, Salvador. Anais... Salvador: UFBA, 2005. Disponível em: <http://dici.ibict. br/archive/00000263/01/Preserva\%C3\%A7\%C3\%A3o_VI_CINFORM.pdf>. Acesso em: 30 mar. 2007.

CASTRO, F. F. Padróes de representaçáo e descriçáo de recursos informacionais em bibliotecas digitais na perspectiva da Ciência da Informaçáo: uma abordagem do MarcOnt Initiative na era da Web Semântica. 2008. 203 p. Dissertação (mestrado em Ciência da Informação) - UNESP - Universidade Estadual paulista, Marília.

D'ANDRÉA, Carlos. Estratégias de produção e organização de informaçôes na web: conceitos para a análise de documentos na internet. Ciência da Informaçáo, Brasília, v. 35, n. 3, p. 39-44, set./dez. 2006.

LIMA-MARQUES, M; MACEDO, F.L.O. Arquitetura da Informaçáo: Base para a gestão do conhecimento. In: TARAPANOFF, Kira $(\mathrm{Org})$. Inteligência, informação e conhecimento em corporações. Brasília: IBICT, UNESCO, 2006.

LOUREIRO, I.M.A; ALBAGLI, S. O papel do ambiente informacional na geração do conhecimento e inovação. In: ENANCIB - ENCONTRO NACIONAL DA CIÊNCIA DA INFORMAÇÃO BRASILEIRA, IX, 2008, São Paulo. Anais... São Paulo: SENAC, 2008. Disponível em: <http://www.enancib2008.com.br/cd/6\%20-\%20Trabalhos\%20em\%20PDF/ GT5/Oral/1679\%20-\%20O\%20papel\%20do\%20ambiente\%20informacional\%20na\%20 geração\%20d....pdf>. Acesso em: 06 out. 2008.

McGEE, J; PRUSAK, L. Gerenciamento Estratégico da Informação. Tradução: Astrid Beatriz de Figueiredo. Rio de Janeiro: Campus, p.129-149, 1994.

MOBASHER, B; DAI, H; LUO, T; NAKAGAWA, M.Effective Personalization Based on Association Rule Discovery from Web Usage Data. ACM - Proceedings of the 3rd international workshop on Web information and data management. p. 9-15, 2001. Disponível em: http://portal.acm.org/ft_gateway.cfm?id=502935\&type=pdf\&coll=Portal $\&$ $\mathrm{dl}=\mathrm{ACM} \& \mathrm{CFID}=29687628 \& \mathrm{CFTOKEN}=12483935$. Acesso em: 05 mai. 2008.

MORVILLE, P; ROSENFELD, L. Information Architecture for the World Wide Web. Sebastopol, CA: O’Reilly, 2006. 504p. 
NOVELliNO, Maria Salet Ferreira. Instrumentos e Metodologias de Representação da Informação. Informaçáo \& Informaçáo, Londrina, v.1, n.2, p.37-45, jul./dez. 1996. Disponível em:<http://www.uel.br/revistas/uel/index.php/informacao/article/view/1603/1358>. Acesso em: 24 mai. 2009.

OLIVEIRA, Leonardo Bueno de. Arquitetura da Informaçáo aplicada na construçáo de um sistema publicador para Jornais Digitais. Dissertação (Mestrado em Jornalismo). Escola de Comunicação e Artes da Universidade de São Paulo, 2005. Disponível em : <http://www. dominiopublico.gov.br/download/texto/cp012396.pdf>. Acesso em: 27 mai. 2008.

PRESSMAN, R. Engenharia de Software. McGraw-Hill, 2006.

PINTO, Virgínia Bentes. Indexação documentária: uma forma de representação do conhecimento registrado. Perspectiva em Ciência da Informaçáo., Belo Horizonte, v. 6, n. 2, p. 223 - 234, jul./dez. 2001. Disponível em: < http://www.eci.ufmg.br/pcionline/index.php/pci/ article/viewFile/423/239>. Acesso em: 01 jun. 2009.

ROSENFELD, L; MORVILLE, P. Information Architecture for the World Wide Web. Sebastopol, CA: O'Reilly, 1998. 202p.

ROSETTO, M. Metadados e formatos de metadados em sistemas de informaçáo: caracterização e definição. 2003. 95 f. Dissertação (Mestrado em Ciências da Comunicação) - Escola de Comunicações e Artes, Universidade de São Paulo, São Paulo.

SCHILKE S.W; BLEIMANN, U; FURNELL, S.M; PHIPPEN, A.D.Multidimensionalpersonalisation for location and interestbased recommendation. Internet Research, v. 14, n.5, 2004, p. 379-385. Emerald Group Publishing Limited 1066-2243. DOI 10.1108/10662240410566980. Disponível em: < www.emeraldinsight.com/10662243.htm>. Acesso em: 28 mai. 2008.

SILVINO, A. M. D; ABRAHÂO, J.I. Navegabilidade e Inclusão Digital: Usabilidade e Competência. RAE-eletrônica, v. 2, n. 2, jul-dez/2003. Disponível em: <http://www.rae. com.br/artigos/1808.pdf>. Acesso em: 25 out. 2007.

SIQUEIRA, André Henrique de. A Lógica e a Linguagem como Fundamentos da Arquitetura da Informaçáo. 2008. 143 p. Dissertação (Mestrado em Ciência da Informação e Documentação) UnB - Universidade de Brasília. Disponível em: <http://bdtd.bce.unb. br/tedesimplificado/tde_busca/arquivo.php?codArquivo=3180> Acesso em: 20 mai. 2008. TOMS, E.G; BLADES, R.L. Information Architecture and web site design. Feliciter, v.45, n.4, 1999. Disponível em: <http://www.cla.ca/feliceter/45-4/column2.htm>. Acesso em: 29 fev. 2004.

TORRES, E. F.; MAZZONI, A. M.; ALVES, J. B. M. A acessibilidade à informação no espaço digital. Ciência da Informaçáo, Brasília, v. 31, n. 3, p. 83-91, set./dez. 2002.

TOSETE HERRANZ, F; RODRIGUEZ MATEOS, D. Arquitectura de la información y el diseńo de sedes web. Universidad Carlos III de Madrid. IN: SEBASTIAN, Mercedes Caridad; FLORES, J. Tomás Nogales (coord.). La Información en la posmodernidad: la sociedad del conocimiento en España e iberoamérica. Editorial universitária Ramón Areces, 2004.

WINCKLER, M; PIMENTA, M.S. Avaliação de Usabilidade de Sites Web. In: ESCOLA REGIONAL DE INFORMÁTICA, 2002, Porto Alegre. Anais... Porto Alegre: SBC, 2002.

Disponível em: <http://www.funtec.org.ar/usabilidadsitiosweb.pdf>. Acesso em: 25 out. 2007.

WURMAN, Richard Saul. Information architects. Zurich, Suíça: Graphis, 1996. 